\title{
Indigenous Community Partnerships towards Foundational Understanding of Wild Salmon Survival
}

\author{
William I. Atlas ${ }^{1}$, William G. Housty ${ }^{2}$, and Jonathan W. Moore $^{3}$ \\ ${ }^{1}$ QQs Projects Society, PO Box 786, Bella Bella BC, VOT 1Z0, Canada \\ ${ }^{2}$ Heiltsuk Integrated Resource Management Department, PO Box 731, Bella Bella, British Columbia V0T 1Z0, \\ Canada \\ ${ }^{3}$ Earth to Oceans Research Group, Simon Fraser University, 8888 University Drive, Burnaby, British Columbia \\ V5A 1S6, Canada
}

Keywords: Indigenous science, sockeye salmon, marine survival, life-cycle monitoring

Salmon are foundational to the ecological and cultural integrity of British Columbia's remote North and Central Coast (NCC). With largely intact habitats, low human population density, and provincially legislated protections under the Great Bear Rainforest Agreement, this remote region supports hundreds of unique, locally adapted populations of salmon, and is critical to the long-term conservation of wild salmon in British Columbia. However, in recent years populations of sockeye salmon and other species on the North and Central Coast have experienced decreases in abundance and productivity (Peterman and Dorner 2012), resulting in declining opportunities for sport, commercial, and First Nation's subsistence fisheries (Connors et al. in review). While declining smolt-to-adult survival has been hypothesized as a possible driver of populations declines (McKinnell et al. 2001), a lack of population monitoring data, and limited understanding of population dynamics currently hinders management and recovery efforts.
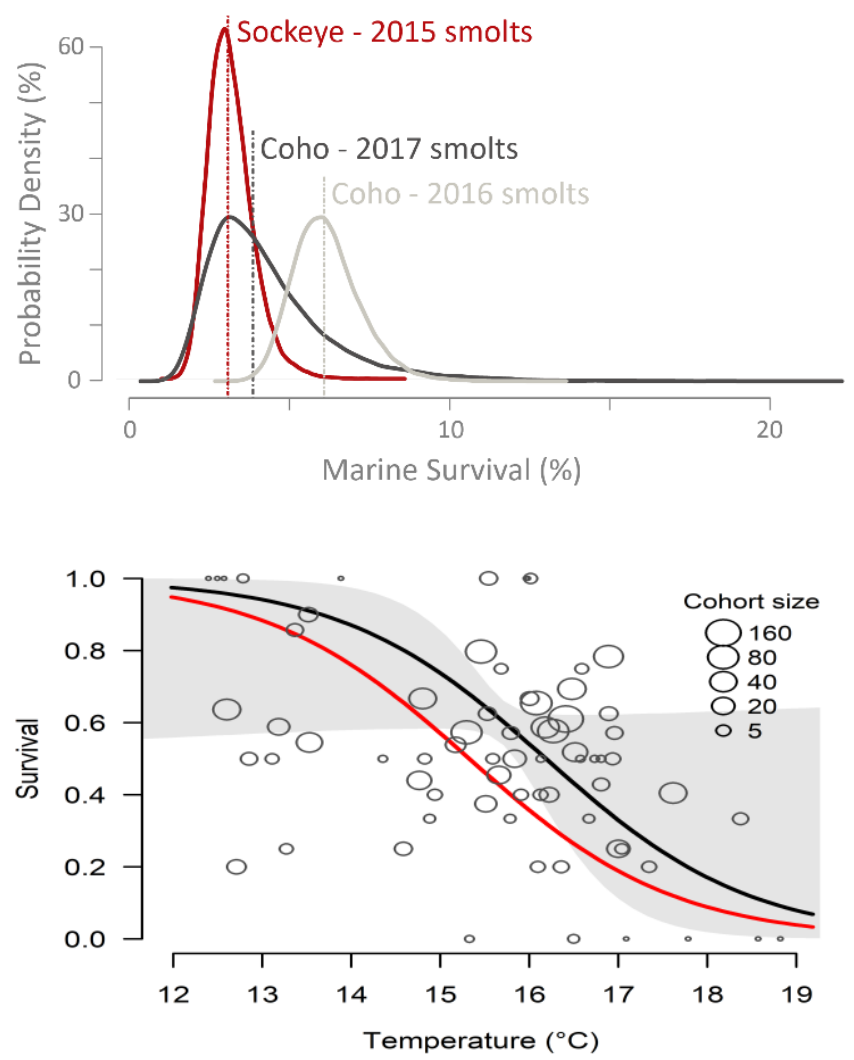

Fig. 1. Probability densities for smolt-to-adult survival estimates among Koeye River sockeye and coho salmon.
Fig. 2. Median estimate and $95 \%$ credible intervals (gray shading) for the relationship between temperature and survival from the model relating survival probability to temperature and injury (model 1). Black and red lines reflect expected survival for a fish without injury and with gillnet or predator injury respectively. Circles represent apparent survival to spawning for each cohort of tagged sockeye, with circle size scaled to the number of fish in each cohort.

In Canada, First Nations play a large and growing role in the management and conservation of wild salmon. These communities trace their ancestry and occupation of their traditional homelands back more than 10,000 years, and salmon are among the most important traditional foods for coastal Indigenous people (Marushka et al. 2019). 
The Koeye River is a major salmon bearing river in the traditional territory of the Heiltsuk Nation. Since 2013, we have run a collaborative life-cycle monitoring program in the Koeye River. Working with the Heiltsuk Nation, QQs Projects Society, the Hakai Institute, and Simon Fraser University, we aim to provide improved monitoring of salmon escapement (Atlas et al. 2017), smolt production, and the role of survival across the freshwater and marine life cycle in driving recruitment variation.

Salmon research in Koeye involves two related components: First, each spring we operate a smolt trap in the lower Koeye River, enumerating sockeye and coho smolts and tagging approximately 2,000 of each species with uniquely coded Passive Integrated Transponder (PIT) tags. These tagged smolts are redetected on a network of inriver Radio Frequency Identification (RFID) antennas when the fish return as adults, allowing us to estimate smoltto-adult survival, and evaluate the role of individual length, condition and migration date on the probability of survival at sea. Second, every year in June we install a weir in the lower Koeye River for sockeye enumeration. Returning adult sockeye are captured and tagged fish visually identifiable FLOY tags as well as PIT tags. This tagging allows us to track the fate of individual adult salmon from river entry to spawning to evaluate the impacts of climate on migration success and make subsequent mark-recapture estimates of sockeye spawner abundance.

Since 2016 an average of about $75 \%$ of tagged adult sockeye have survived to reach the spawning grounds, however, survival among migrating adult sockeye declined dramatically when temperatures exceeded $16^{\circ} \mathrm{C}$. Furthermore, fish with gillnet or predator injuries had a $30 \%$ lower probability of survival to spawning.

Over the first few years of smolt tagging, outmigrant smolts have had variable survival. Sockeye that went to sea in 2015 returned in 2017 and 2018, with an estimated smolt-to-adult survival of 3\% (CI: 1.9-4.6\%). Coho which went to sea in 2016 had an estimated smolt-to-adult survival rate of $6.5 \%$ (CI: 4.5-8.7\%), while coho that went to sea in 2017 had an estimated survival rate of $4 \%$ (CI: 2.0-8.0\%).

These results demonstrate the power of community-led research and monitoring in providing foundational understanding of salmon populations in remote regions like the NCC.

\section{REFERENCES}

Atlas, W.I., W.G. Housty, A. Béliveau, B. DeRoy, G. Callegari, M. Reid, and J.W. Moore. 2017. Ancient fish weir technology for modern stewardship: lessons from community-based salmon monitoring. Ecosystem Health and Sustainability. 3(6): 1341284. doi.org/10.1080/20964129.2017.1341284.

Connors, B.M., W.I. Atlas, C. Melymick, M. Moody, and J. Moody. In press. Conservation risk and uncertainty in recovery prospects for a collapsed and culturally important sockeye salmon population in a mixed-stock fishery. Mar. Coast. Fisheries.

Marushka, L., T. Kenny, M. Batal, W.W.L. Cheung, K. Fediuk, C.D. Golden, A.K. Salomon, T. Sadik, L.V. Weatherdon, and H.M. Chan. 2019. Potential impacts of climate-related decline of seafood harvest on nutritional status of coastal First Nations in British Columbia, Canada. PLoS ONE. 14: e0211473.

McKinnell, S.M., C.C. Wood, D.T. Rutherford, K.D. Hyatt, and D.W. Welch. 2001. The demise of Owikeno lake sockeye salmon. N. Am. J. Fish. Manage. 21: 774-791.

Peterman, R.M., and B. Dorner. 2012. A widespread decrease in productivity of sockeye salmon (Oncorhynchus nerka) populations in western North America. Can. J. Fish. Aquat. Sci. 69: 1255-1260. 